\title{
Impact of KRAS, BRAF and PI3KCA mutations in rectal carcinomas treated with neoadjuvant radiochemotherapy and surgery
}

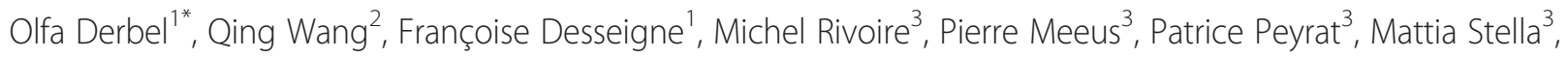
Isabelle Martel-Lafay ${ }^{4}$, Anne-Isabelle Lemaistre ${ }^{5}$ and Christelle de La Fouchardière ${ }^{1}$

\begin{abstract}
Background: Conventional treatment for locally advanced rectal cancer usually combines neoadjuvant radiochemotherapy and surgery. Until recently, there have been limited predictive factors (clinical or biological) for rectal tumor response to conventional treatment. KRAS, BRAF and PIK3CA mutations are commonly found in colon cancers. In this study, we aimed to determine the mutation frequencies of KRAS, BRAF and PIK3CA and to establish whether such mutations may be used as prognostic and/or predictive factors in rectal cancer patients.

Methods: We retrospectively reviewed the clinical and biological data of 98 consecutive operated patients between May 2006 and September 2009. We focused in patients who received surgery in our center after radiochemotherapy and in which tumor samples were available.
\end{abstract}

Results: In the 98 patients with a rectal cancer, the median follow-up time was 28.3 months (4-74). Eight out of ninety-eight patients experienced a local recurrence (8\%) and 17/98 developed distant metastasis (17\%). KRAS, BRAF and PIK3CA were identified respectively in 23 (23.5\%), 2 (2\%) and $4(4 \%)$ patients. As described in previous studies, mutations in KRAS and BRAF were mutually exclusive. No patient with local recurrence exhibited KRAS or PIK3CA mutation and one harbored BRAF mutation (12.5\%). Of the seventeen patients with distant metastasis (17\%), 5 were presenting KRAS mutation (29\%), one BRAF (5\%) and one PIK3CA mutation (5\%). No relationship was seen between PIK3CA, KRAS or BRAF mutation and local or distant recurrences.

Conclusion: The frequencies of KRAS, BRAF and PIK3CA mutations in our study were lower than the average frequencies reported in colorectal cancers and no significant correlation was found between local/distant recurrences and KRAS, BRAF or PIK3CA mutations. Future studies with greater number of patients, longer follow-up time and greater power to predict associations are necessary to fully understand this relationship.

\section{Background}

Over the last decade, the management of colorectal cancer (CRC) has progressed faster than in any other gastrointestinal tumors [1]. These advances have been made especially in metastatic disease, with the introduction of targeted therapies in addition to chemotherapy and the development of metastasis surgery [2-5]. Improvements have also been made in the adjuvant setting with the introduction of the oxaliplatin-based chemotherapy regimen in stage III colon cancer [6]. Less

\footnotetext{
* Correspondence: olfa.derbel@lyon.unicancer.fr

'Department of Medical Oncology, Centre Léon Bérard, 28 rue Laennec, 69008 Lyon, France

Full list of author information is available at the end of the article
}

progress has been made in the management of rectal cancer. Radiochemotherapy based on 5FU regimen, followed by total mesorectum excision (TME) represents the optimal combined treatment for locally advanced rectal cancer (defined as T3 and/or $\mathrm{N}+$ disease) $[7,8]$. Neoadjuvant radiochemotherapy has been shown to reduce local recurrences and to increase pathological complete response compared with radiotherapy and surgery [9-11]. This preoperative modality is currently preferred to the postoperative one because of a significantly lower local recurrence rate, improved sphincter preservation and less toxicity $[12,13]$. Attempts to increase the benefit of radiochemotherapy have been tried, especially with the introduction of oxaliplatin in addition to 
capecitabine but finally, the 5FU based radiochemotherapy has remained the standard treatment for patients with locally-advanced rectal cancer [9,13-15]. The decision to use neoadjuvant radiochemotherapy is based on a pretreatment tumor staging defining the $\mathrm{T}$ and the $\mathrm{N}$ stage with pelvic MRI and endorectal ultrasound. The tumor response is evaluated by the pathological examination of the operative specimen. It is well known that downstaging after radiochemotherapy has been shown to predict fewer recurrences and better prognosis $[13,16]$. However, the decision to use neoadjuvent radiochemotherapy is complex. First, the tumor response can be evaluated only after the pathological examination. Secondly, despite low local recurrence rates, patients with initially localized rectal cancer continue to have high mortality because of secondary metastases (15-35\%). On the other hand, some patients may be over treated with radiochemotherapy. Therefore, many authors have tried to identify predictive factors to anticipate radiochemotherapy response. Currently, the best available methods to investigate improved outcomes in rectal cancer include accurate early assessment of tumor response with MRI and identifying predictive molecular tumor abnormalities.

KRAS, BRAF and PIK3CA mutations are commonly found in colorectal cancers. KRAS and BRAF genes can harbor oncogenic mutations that yield a constitutively active protein and are found in approximately $30-50 \%$ and $10-15 \%$ of CRC tumors, respectively $[17,18]$. Several studies have indicated that the presence of mutant KRAS in CRC tumors correlates with poor response to EGFR in a metastatic setting [5,18-20]. Furthermore, BRAF mutations have been incriminated as poor prognosis factors in metastatic CRC [21]. However, the impact of KRAS and BRAF mutations on clinical outcome of patients with locally advanced CRC are unknown. Regarding PIK3CA, a large cohort study has recently shown that PIK3CA mutation was associated with poor prognosis among patients with resectable stage I to III colon cancer [22]. Another large population-based study in colon cancer suggested that the activation of the PI3K/AKT or the RAS-RAF-MAPK pathway by mutation of at least one of the three genes predicted poor patient outcome, but the effect of mutations in PIK3CA alone was not discussed [17]. Another previous study of a small cohort of colorectal cancer patients reported that PIK3CA mutation is predictive of poor survival [23]. Recently, He et al. showed that PIK3CA mutations were strongly associated with a high risk of local recurrences in non irradiated stage I to III rectal cancer patients [24]. As their population was heterogeneous in tumor stage (I to III) and was not treated with combined modality therapy, we aimed to corroborate the mutation frequencies of KRAS, BRAF and PIK3CA in rectal cancer and to establish whether such mutations may be used as prognostic and/or predictive factors in multimodal treated rectal cancer patients. This study is the first to look at all three mutations in locally advanced rectal (not colorectal) cancer in patients treated with neoadjuvent chemotherapy and surgery.

\section{Methods}

\section{Patients and tumor samples}

The clinical records of all consecutively patients with locally advanced rectal carcinoma (clinical T3 or T4 or nodepositive) referred to the Centre Leon Berard between May 2006 and September 2009 were reviewed. The study was approved by the ethic committee of Leon Berard Center. Written informed consent was obtained for all patients.

The inclusion criteria were a confirmed diagnosis of rectal adenocarcinoma and available tumor sample. All patients gave their informed consent for this research. Diagnosis was established on the basis of histological features and was confirmed by immunochemical staining. Pathology procedures were standardized and quality controlled. Prior to treatment, a history and physical exam were completed for all patients as well as assessment of performance status, complete blood counts ( $\mathrm{CBCs}$ ), liver function creatinine, and serum carcinoembryogenic antigen. All patients underwent before treatment a rigid rectoscopy and a total colonoscopy. Tumor and nodal stage was evaluated with pelvic MRI and/or an endorectal ultrasound. Metastatic extension was eliminated with a chest- abdomen-pelvis computed tomography. Clinical tumor staging was finally defined with the "i" (MRI) or " $\mathrm{u}$ " (ultrasound) tumor-node-metastasis (TNM) classification. Clinical examination and CBCs were repeated every week during radiochemotherapy. Four weeks after the end of radiochemotherapy, clinical tumor stage was re-evaluated with pelvic MRI and CT. After surgery, patients were assessed every 3 months during the first two years and every 6 months during years 3 to 5 .

Patients were treated with neoadjuvant radiochemotherapy and TME-surgery. Radiotherapy consisted on 45 to 50 Gy in 25 fractions of 1.8 to 2Gy with concurrent intravenous 5FU or capecitabine. Oral capecitabine 800 $\mathrm{mg} / \mathrm{m} 2$ twice daily was started on the first day of radiotherapy and given 5 days per week during radiotherapy. When used, infusional 5FU was given at a dose of $350 \mathrm{mg} / \mathrm{m} 2 / \mathrm{d}$ from Monday to Friday with leucovorin at a dose of $20 \mathrm{mg} / \mathrm{m} 2 / \mathrm{d}$. Surgery was planned 6 weeks after the end of preoperative radiochemotherapy. Total mesorectal excision was performed according to a standardized technique.

\section{DNA extraction and mutation analysis}

DNA was amplified with specific primers for exons where "hot-spot" mutations are located. DNA was extracted from FFPE primary tumor samples using QIAamp DNA FFPE 
Tissue Kit (Qiagen, Hilden, Germany). Mutation status of KRAS gene (exon 2 and 3), PIK3CA gene (exon 9 and exon 20), BRAF gene (exon 15), was investigated by PCR amplification followed by direct sequencing using $\mathrm{ABI}$ 3730 automated sequencer (life Technologies). The oligo sequences of primers used for analyses are available upon request.

\section{Statistical analysis}

All statistical analyses were done with SPSS statistical software (version 15.0 for Windows, SPSS, Inc). $\chi^{2}$ test and Fisher's exact test were used to compare proportions. Recurrences and survival analyses were done using the Kaplan-Meier method with time of surgery as entry date. Logrank testing was used for comparison of groups.

\section{Results}

Patient characteristics

Ninety-eight consecutive patients treated at the Centre Leon Berard, Lyon, France for an advanced rectal cancer between May 2006 and September 2009 met the inclusion criteria. Locally advanced rectal cancer was defined as T3 and/or $\mathrm{N}+$ disease with pelvic MRI and/or endorectal ultrasound. Median follow-up was 28.3 months (4-74). Patient's characteristics are listed in Table 1.

\section{Pathologic characteristics}

We correlated the KRAS, BRAF and PIK3CA genotypes with clinicopathological features of $C R C$, including primary tumour location, histological findings, and sites of metastases. There was no correlation between mutations and clinicopathologic features, including age, gender, tumor location, type of resection, circumferential margin (CRM), differentiation grade, lymph node and TNM stage. We also investigated whether KRAS, BRAF or PIK3CA mutations may confer radioresistance and reduced response to CRT. There was no difference in residual tumor status or in response to chemoradiation as assessed by tumor downstaging, based on mutations status.

\section{Mutation analysis}

KRAS, BRAF and PIK3CA were identified respectively in 23 (23.5\%), 2 (2\%) and $4(4 \%)$ patients. The most frequent mutation at KRAS was G13D which accounted for $43 \%$ of KRAS mutations (10/23). The codon 12 mutations were the G12D (5/23), G12V (4/23), G12S (2/23), G12R (1/23) and G12C (1/23). BRAF V600E mutation was identified in one patient (50\%). Mutations are summarized in Table 1 and the distribution of the mutations is shown in Figure 1. As described in previous studies, mutations in $K R A S$ and $B R A F$ were mutually exclusive.
Table 1 Clinical and molecular characteristics of 98 patients with rectal carcinoma

\begin{tabular}{|c|c|}
\hline Clinical and molecular characteristics & No patients $n=98(\%)$ \\
\hline \multicolumn{2}{|l|}{ Sex } \\
\hline Male & $50(51)$ \\
\hline Female & $48(49)$ \\
\hline Age. y median & $68(35-88)$ \\
\hline \multicolumn{2}{|l|}{ Distance to anal verge. $\mathrm{cm}$} \\
\hline$\geq 10$ & $25(25.5)$ \\
\hline $5 \leq<10$ & $26(26.5)$ \\
\hline$<5$ & $40(41.8)$ \\
\hline Not avaibale & $7(7.2)$ \\
\hline \multicolumn{2}{|l|}{ Type of resection } \\
\hline Low anterior & $8(8.1)$ \\
\hline Abdominoperineal & $90(91.9)$ \\
\hline \multicolumn{2}{|l|}{ CRM } \\
\hline Negative & $88(89.8)$ \\
\hline Positive & $3(3.1)$ \\
\hline Not avaiballe & $7(7.1)$ \\
\hline \multicolumn{2}{|l|}{ Differentiation } \\
\hline Well & $15(15.1)$ \\
\hline Moderate & $51(52.1)$ \\
\hline Poor & $10(10.3)$ \\
\hline Not avaibale & $22(22.5)$ \\
\hline \multicolumn{2}{|l|}{ TNM stage } \\
\hline । & $6(6.1)$ \\
\hline$\|$ & $86(87.8)$ \\
\hline$\|$ & $6(6.1)$ \\
\hline \multicolumn{2}{|l|}{ KRAS mutation } \\
\hline Yes & $23(23.5 \%)$ \\
\hline No & $75(76.5)$ \\
\hline \multicolumn{2}{|l|}{ BRAF mutation } \\
\hline Yes & $2(2 \%)$ \\
\hline No & 96 (98\%) \\
\hline \multicolumn{2}{|l|}{ PIK3CA mutation } \\
\hline Yes & $4(4 \%)$ \\
\hline No & $94(96 \%)$ \\
\hline \multicolumn{2}{|l|}{ Local recurrence } \\
\hline Negative & $90(91.8)$ \\
\hline Positive & $8(8.2)$ \\
\hline \multicolumn{2}{|l|}{ Distant metastasis } \\
\hline Negative & 81 (82.6) \\
\hline Positive & $17(17.4)$ \\
\hline
\end{tabular}




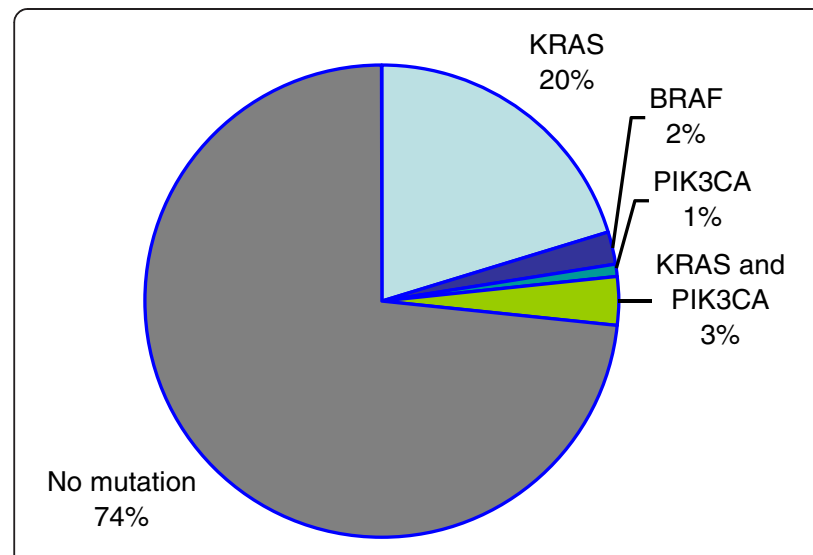

Figure 1 The distribution of mutations is illustrated in a pie chart.

\section{Correlation with local and metastatic recurrences}

With a median follow-up time of 28.3 months (4-74), 8 patients experienced a local recurrence (8\%) and 17 developed distant metastasis (17\%). No patient with local recurrence exhibited KRAS or PIK3CA mutation and one harbored $B R A F$ mutation (12.5\%). Among the seventeen patients (17\%) with distant metastasis, 5 were harboring KRAS mutation (29\%), one BRAF (5\%) and one KRAS mutation (5\%). Survival analyses compared results for patients with each mutation, patients with at least one of the 3 mutations versus those who had no mutations (Tables 2 and 3).

Table 2 Mutational status and local recurrence

\begin{tabular}{|c|c|c|c|c|c|c|}
\hline & \multicolumn{4}{|c|}{ Local recurrence } & \multicolumn{2}{|c|}{ Patients } \\
\hline & \multicolumn{2}{|c|}{ No } & \multicolumn{2}{|r|}{ Yes } & & \\
\hline & \multicolumn{2}{|c|}{$\mathrm{N}=90$} & \multicolumn{2}{|r|}{$\mathrm{N}=8$} & \multicolumn{2}{|c|}{$\mathrm{N}=98$} \\
\hline \multicolumn{7}{|c|}{ KRAS Mutation } \\
\hline No & 67 & (74.4\%) & 8 & $(100.0 \%)$ & 75 & (76.5\%) \\
\hline yes & 23 & $(25.6 \%)$ & 0 & $(0.0 \%)$ & 23 & $(23.5 \%)$ \\
\hline \multicolumn{7}{|c|}{ BRAF Mutation } \\
\hline No & 89 & (98.9\%) & 7 & $(87.5 \%)$ & 96 & (98.0\%) \\
\hline yes & 1 & $(1.1 \%)$ & 1 & $(12.5 \%)$ & 2 & $(2.0 \%)$ \\
\hline \multicolumn{7}{|c|}{ PIK3CA Mutation } \\
\hline No & 86 & $(95.6 \%)$ & 8 & $(100.0 \%)$ & 94 & (95.9\%) \\
\hline yes & 4 & $(4.4 \%)$ & 0 & $(0.0 \%)$ & 4 & $(4.1 \%)$ \\
\hline \multicolumn{7}{|c|}{ All mutations } \\
\hline \multicolumn{7}{|c|}{ At least one mutation } \\
\hline No & 65 & $(72.2 \%)$ & 7 & $(87.5 \%)$ & 72 & (73.5\%) \\
\hline yes & 25 & $(27.8 \%)$ & 1 & $(12.5 \%)$ & 26 & $(26.5 \%)$ \\
\hline \multicolumn{7}{|c|}{$\mathrm{Nb}$ of mutations } \\
\hline 0 & 65 & $(72.2 \%)$ & 7 & $(87.5 \%)$ & 72 & $(73.5 \%)$ \\
\hline 1 & 22 & $(24.4 \%)$ & 1 & $(12.5 \%)$ & 23 & $(23.5 \%)$ \\
\hline 2 & 3 & $(3.3 \%)$ & 0 & $(0.0 \%)$ & 3 & $(3.1 \%)$ \\
\hline
\end{tabular}

Table 3 Mutational status and metastatic recurrence

\begin{tabular}{|c|c|c|c|c|c|c|c|}
\hline & \multicolumn{4}{|c|}{ Metastatic recurrence } & \multirow{2}{*}{\multicolumn{2}{|c|}{ Patients }} & \multirow[t]{3}{*}{ Test } \\
\hline & \multirow{2}{*}{\multicolumn{2}{|c|}{$\begin{array}{c}\text { No } \\
\mathrm{N}=81\end{array}$}} & \multirow{2}{*}{\multicolumn{2}{|c|}{$\begin{array}{c}\text { Yes } \\
N=17\end{array}$}} & & & \\
\hline & & & & & \multicolumn{2}{|r|}{$\mathrm{N}=98$} & \\
\hline \multicolumn{8}{|l|}{ KRAS mutation } \\
\hline Non & 63 & $(77.8 \%)$ & 12 & $(70.6 \%)$ & 75 & $(76.5 \%)$ & \\
\hline Yes & 18 & $(22.2 \%)$ & 5 & $(29.4 \%)$ & 23 & $(23.5 \%)$ & \\
\hline BRAF mutation & & & & & & & Fisher Exact \\
\hline Non & 80 & $(98.8 \%)$ & 16 & (94.1\%) & 96 & $(98.0 \%)$ & \\
\hline Yes & 1 & $(1.2 \%)$ & 1 & $(5.9 \%)$ & 2 & $(2.0 \%)$ & \\
\hline PIK3CA mutation & & & & & & & Fisher Exact \\
\hline Non & 78 & $(96.3 \%)$ & 16 & (94.1\%) & 94 & $(95.9 \%)$ & \\
\hline Yes & 3 & $(3.7 \%)$ & 1 & $(5.9 \%)$ & 4 & $(4.1 \%)$ & \\
\hline \multicolumn{8}{|l|}{ All mutations } \\
\hline $\begin{array}{l}\text { At least one } \\
\text { mutation }\end{array}$ & & & & & & & $\begin{array}{c}\text { Fisher Exact } \\
P=0.377\end{array}$ \\
\hline No & 61 & $(75.3 \%)$ & 11 & $(64.7 \%)$ & 72 & $(73.5 \%)$ & \\
\hline Yes & 20 & $(24.7 \%)$ & 6 & $(35.3 \%)$ & 26 & $(26.5 \%)$ & \\
\hline $\mathrm{Nb}$ of mutations & & & & & & & Fisher Exact \\
\hline 0 & 61 & $(75.3 \%)$ & 11 & $(64.7 \%)$ & 72 & $(73.5 \%)$ & \\
\hline 1 & 18 & $(22.2 \%)$ & 5 & $(29.4 \%)$ & 23 & $(23.5 \%)$ & \\
\hline 2 & 2 & $(2.5 \%)$ & 1 & (5.9\%) & 3 & (3.1\%) & \\
\hline
\end{tabular}

No relationship was seen between PIK3CA, KRAS or $B R A F$ mutation and local or distant recurrences and no longer with overall survival (all $\mathrm{p}<0.01$ ).

\section{Discussion}

Despite the recent advances in the management of metastatic colorectal cancer (mCRC) over the last few years, this disease remains a major public health problem in the world [1]. Its prognosis has been improved, but recurrences remain a clinical challenge. Local recurrences are a critical issue in rectal cancer and several tumor characteristics are associated with local recurrence, including depth of tumour invasion into and beyond the bowel wall, number of lymph nodes involved by tumor cells, extramural venous invasion, involvement of the circumferential resection margin (CRM) and the tumor location within $10 \mathrm{~cm}$ from anal verge. These factors may be used in therapeutic decisions regarding administration of (neo) adjuvant treatment [25]. However, patients with similar clinicopathologic characteristics still display a large variation in prognosis, suggesting that the biology of the tumor may be responsible for the difference. The detection of biological predictive markers may improve the selection of patients who will benefit from (neo) adjuvant treatment and spare patients who will only experience side effects. The MAPK pathway plays a major role in cell proliferation and is involved in up to $30 \%$ of CRC [26]. Both KRAS and BRAF are the members of this 
signalling pathway and are known to be activated by oncogenic mutations. KRAS mutations, are reported in 19 to $48 \%$ of patients with rectal cancer [1,24-27], whereas $B R A F$ mutations are found in 0 to $12 \%$ of $\mathrm{RC}$ patients $[28,29]$. The mutation frequency reported in our study (23\% for $K R A S$ and $2 \%$ for BRAF) are in concordance with those reported in literature. The rarity of V600E BRAF mutations in rectal cancer has been previously described in reports from Di Nicolantonio et al. [30] who found 1 V600E allele in 43 rectal samples and Fransen et al. [28] who even found 2 mutations in 55 rectal cancers.

In our study, we identified a $4 \%$ incidence for PIK3CA mutations, which is lower than the $10 \%$ to $30 \%$ reported in colon cancer. The first study in colorectal cancer reported that PIK3CA mutations were significantly associated with poor survival [23]. They further identified PIK3CA mutations as the only independent and significant prognostic factor for relapse-free survival in stage II to III patients. However, there were only 18 PIK3CA-mutated tumors and the number of deaths was not reported. Another study has shown that the presence of at least one mutation in PIK3CA, BRAF, or KRAS genes predicts poor survival in a population-based colon cancer samples, however, the effect of PIK3CA mutations on survival, independently of clinical and other molecular predictors of outcome, was not described [31]. In a recent study, Ogino et al. examined the prognostic significance of PIK3CA mutations among 450 patients who had undergone a curative resection of colon cancer. They found that PIK3CA mutations were associated with a decreased survival. The "poor prognosis" effect of PIK3CA mutations seemed to be robust and consistent across most strata of clinical and tumoral predictors of patient outcome, but this effect seems to be limited to patients with KRAS wildtype tumors [22]. Additionally, these mutation studies make no distinction between rectal and colic cancer. A recent study determined the prognostic value of PIK3CA mutations in 240 non- irradiated resectable stages I to III rectal cancer patients from the Dutch TME trial. PIK3CA mutations were identified in 19 (7.9\%) of the 240 patients and revealed a strong association with an increased local recurrence rate. Moreover, tumors with PIK3CA mutations showed a tendency to develop local recurrences more rapidly after surgery [24].

A second analysis by $\mathrm{He}$ et al. was published in 2010 concerning the results in irradiated patients from the total mesorectal excision (TME) trial. In this population, they investigated whether PIK3CA mutant patients benefit from preoperative radiotherapy. Although the difference was not statistically significant, it suggests that PIK3CA mutant patients seem to benefit from irradiation in preventing LR [32].

Several studies have focused on KRAS mutation and radioresistance, with controversial conclusions. Michelassi et al. found that tumor downstaging was associated with KRAS wild type tumors [33] and Grana et al. reported that KRAS mutations potentially mediate resistance to ionizing radiation [34]. Other studies reported no change in downstaging by KRAS status $[29,35,36]$ and even when adjusting the groups according to the codon which carried the mutation, failed to predict response to preoperative CT/RT. In a recent study, Davies showed that KRAS mutational status was not associated with radiosensitivity using more modern sequencing technology in a larger number of patients than previously described [37]. Interestingly, they reported that activation of AKT and ERK is correlated with response to radiation therapy [37].

\section{Conclusions}

In summary, our retrospective study failed to confirm a significant correlation between KRAS, BRAF or PIK3CA mutations as predictive factors of local or distant recurrence, following preoperative RT/CT. The exact effects of KRAS, BRAF and PIK3CA mutations on recurrence require further study with analyses of a larger patient population because the number of relapse events was very small and may represent a sample bias. Finally, the follow-up period was probably too short to draw definitive conclusions.

\section{Competing interest}

The authors declare that they have no competing interests.

\section{Authors' contributions}

All authors collected data, reviewed the draft, provided comments or substantive revisions, and approved the final manuscript. All authors read and approved the final manuscript

\section{Author details}

'Department of Medical Oncology, Centre Léon Bérard, 28 rue Laennec, 69008 Lyon, France. '2Department of Biopathology, Centre Léon Bérard, 28 rue Laennec, 69008 Lyon, France. ${ }^{3}$ Department of Surgery, Centre Léon Bérard, 28 rue Laennec, 69008 Lyon, France. ${ }^{4}$ Department of Radiotherapy, Centre Léon Bérard, 28 rue Laennec, 69008 Lyon, France. ${ }^{5}$ Department of Anatomopathology, Centre Léon Bérard, 28 rue Laennec, 69008 Lyon, France.

Received: 14 November 2012 Accepted: 9 April 2013

Published: 23 April 2013

\section{References}

1. Jemal A, Bray F, Center MM, Ferlay J, Ward E, Forman D: Global cancer statistics. CA Cancer J Clin 2011, 61(2):69-90.

2. Hurwitz H, Fehrenbacher L, Novotny W, Cartwright T, Hainsworth J, Heim W, Berlin J, Baron A, Griffing S, Holmgren E, Ferrara N, Fyfe G, Rogers B, Ross R, Kabbinavar F: Bevacizumab plus irinotecan, fluorouracil, and leucovorin for metastatic colorectal cancer. N Engl J Med 2004, 350(23):2335-2342. doi:10.1056/NEJMoa032691.

3. Abdalla EK, Vauthey JN, Ellis LM, Ellis V, Pollock R, Broglio KR, Hess K, Curley $\mathrm{SA}$ : Recurrence and outcomes following hepatic resection, radiofrequency ablation, and combined resection/ablation for colorectal liver metastases. Ann Surg 2004, 239(6):818-825.

4. Adam R, Wicherts DA, de Haas RJ, Ciacio O, Levi F, Paule B, Ducreux M, Azoulay D, Bismuth $\mathrm{H}$, Castaing D: Patients with initially unresectable colorectal liver metastases: is there a possibility of cure? J Clin Oncol 2009, 27(11):1829-1835.

5. Van CE, Kohne CH, Lang I, Folprecht G, Nowacki MP, Cascinu S, Shchepotin I, Maurel J, Cunningham D, Tejpar S, Schlichting M, Zubel A, Celik I, Rougier P, Ciardiello F: Cetuximab plus irinotecan, fluorouracil, and leucovorin as first-line treatment for metastatic colorectal cancer: updated analysis of 
overall survival according to tumor KRAS and BRAF mutation status. J Clin Oncol 2011, 29(15):2011-2019.

6. Andre T, Boni C, Navarro M, Tabernero J, Hickish T, Topham C, Bonetti A, Clingan P, Bridgewater J, Rivera F, de Gramont A: Improved overall survival with oxaliplatin, fluorouracil, and leucovorin as adjuvant treatment in stage II or III colon cancer in the MOSAIC trial. J Clin Oncol 2009, 27(19):3109-3116.

7. Heald RJ, Ryall RD: Recurrence and survival after total mesorectal excision for rectal cancer. Lancet 1986, 1(8496):1479-1482.

8. Kapiteijn E, Marijnen CA, Nagtegaal ID, Putter H, Steup WH, Wiggers T, Rutten HJ, Pahlman L, Glimelius B, van Krieken JH, Leer JW, van de Velde CJ: Preoperative radiotherapy combined with total mesorectal excision for resectable rectal cancer. N Engl J Med 2001, 345(9):638-646. doi:10.1056/NEJMoa010580.

9. Bosset JF, Collette L, Calais G, Mineur L, Maingon P, Radosevic-Jelic L, Daban A, Bardet E, Beny A, Ollier JC: Chemotherapy with preoperative radiotherapy in rectal cancer. N Engl J Med 2006, 355(11):1114-1123.

10. Bujko K, Nowacki MP, Nasierowska-Guttmejer A, Michalski W, Bebenek M, Kryj M: Long-term results of a randomized trial comparing preoperative short-course radiotherapy with preoperative conventionally fractionated chemoradiation for rectal cancer. Br J Surg 2006, 93(10):1215-1223. doi:10.1002/bjs.5506.

11. Gerard JP, Conroy T, Bonnetain F, Bouche O, Chapet O, Closon-Dejardin MT, Untereiner M, Leduc B, Francois E, Maurel J, Seitz JF, Buecher B, Mackiewicz $R$, Ducreux M, Bedenne L: Preoperative radiotherapy with or without concurrent fluorouracil and leucovorin in T3-4 rectal cancers: results of FFCD 9203. J Clin Oncol 2006, 24(28):4620-4625.

12. Pahlman L, Glimelius B: Pre- or postoperative radiotherapy in rectal and rectosigmoid carcinoma. Report from a randomized multicenter trial. Ann Surg 1990, 211(2):187-195.

13. Sauer R, Becker H, Hohenberger W, Rodel C, Wittekind C, Fietkau R, Martus P, Tschmelitsch J, Hager E, Hess CF, Karstens JH, Liersch T, Schmidberger H Raab R: Preoperative versus postoperative chemoradiotherapy for rectal cancer. N Engl J Med 2004, 351(17):1731-1740

14. Aschele C, Cionini L, Lonardi S, Pinto C, Cordio S, Rosati G, Artale S, Tagliagambe A, Ambrosini G, Rosetti P, Bonetti A, Negru ME, Tronconi MC, Luppi G, Silvano G, Corsi DC, Bochicchio AM, Chiaulon G, Gallo M, Boni L: Primary Tumor Response to Preoperative Chemoradiation With or Without Oxaliplatin in Locally Advanced Rectal Cancer: Pathologic Results of the STAR-01 Randomized Phase III Trial. J Clin Oncol 2011, 29(20):2773-2780.

15. Gerard JP, Azria D, Gourgou-Bourgade S, Martel-Laffay I, Hennequin C, Etienne PL, Vendrely V, Francois E, de La RG, Bouche O, Mirabel X, Denis B, Mineur L, Berdah JF, Mahe MA, Becouarn Y, Dupuis O, Lledo G, MontotoGrillot C, Conroy T: Comparison of two neoadjuvant chemoradiotherapy regimens for locally advanced rectal cancer: results of the phase III trial ACCORD 12/0405-Prodige 2. J Clin Oncol 2010, 28(10):1638-1644.

16. Gunderson LL, Sargent DJ, Tepper JE, Wolmark N, O'Connell MJ, Begovic M, Allmer C, Colangelo L, Smalley SR, Haller DG, Martenson JA, Mayer RJ, Rich TA Ajani JA, MacDonald JS, Willett CG, Goldberg RM: Impact of T and N stage and treatment on survival and relapse in adjuvant rectal cancer: a pooled analysis. J Clin Oncol 2004, 22(10):1785-1796. doi:10.1200/JCO.2004.08.173.

17. de Campos-Lobato LF, Stocchi L, da Luz MA, Kalady MF, Geisler D, Dietz D, Lavery IC, Remzi FH, Fazio WW: Downstaging without complete pathologic response after neoadjuvant treatment improves cancer outcomes for clll but not cll rectal cancers. Ann Surg Oncol 2010, 17(7):1758-1766. doi:10.1245/s10434-010-0924-4

18. Schubbert S, Bollag G, Lyubynska N, Nguyen H, Kratz CP, Zenker M, Niemeyer CM, Molven A, Shannon K: Biochemical and functional characterization of germ line KRAS mutations. Mol Cell Biol 2007, 27(22):7765-7770.

19. Lievre A, Laurent-Puig P: Genetics: Predictive value of KRAS mutations in chemoresistant CRC. Nat Rev Clin Oncol 2009, 6(6):306-307.

20. Lievre A, Bachet JB, Le CD, Boige V, Landi B, Emile JF, Cote JF, Tomasic G, Penna C, Ducreux M, Rougier P, Penault-Llorca F, Laurent-Puig P: KRAS mutation status is predictive of response to cetuximab therapy in colorectal cancer. Cancer Res 2006, 66(8):3992-3995.

21. Bokemeyer C, Bondarenko I, Hartmann JT, De Braud F, Schuch G, Zubel A, Celik I, Schlichting M, Koralewski P: Efficacy according to biomarker status of cetuximab plus FOLFOX-4 as first-line treatment for metastatic colorectal cancer: the OPUS study. Ann Oncol 2011, 22(7):1535-1546.

22. Ogino S, Nosho K, Kirkner GJ, Shima K, Irahara N, Kure S, Chan AT, Engelman $J A$, Kraft P, Cantley LC, Giovannucci EL, Fuchs CS: PIK3CA mutation is associated with poor prognosis among patients with curatively resected colon cancer. J Clin Oncol 2009, 27(9):1477-1484

23. Kato S, lida S, Higuchi T, Ishikawa T, Takagi Y, Yasuno M, Enomoto M, Uetake H, Sugihara K: PIK3CA mutation is predictive of poor survival in patients with colorectal cancer. Int J Cancer 2007, 121(8):1771-1778. doi:10.1002/ijc.22890.

24. He Y, Van't Veer LJ, Mikolajewska-Hanclich I, van Velthuysen ML, Zeestraten EC, Nagtegaal ID, van de Velde CJ, Marijnen CA: PIK3CA mutations predict local recurrences in rectal cancer patients. Clin Cancer Res 2009, 15(22):6956-6962.

25. Dresen RC, Peters EE, Rutten HJ, Nieuwenhuijzen GA, Demeyere TB, van den Brule AJ, Kessels AG, Beets-Tan RG, van Krieken JH, Nagtegaal ID: Local recurrence in rectal cancer can be predicted by histopathological factors. Eur J Surg Oncol 2009, 35(10):1071-1077.

26. Hoshino R, Chatani Y, Yamori T, Tsuruo T, Oka H, Yoshida O, Shimada Y, Ari-i $\mathrm{S}$, Wada H, Fujimoto J, Kohno M: Constitutive activation of the 41-/43-kDa mitogen-activated protein kinase signaling pathway in human tumors. Oncogene 1999, 18(3):813-822. doi:10.1038/sj.onc.1202367.

27. Bengala C, Bettelli S, Bertolini F, Sartori G, Fontana A, Malavasi N, Depenni R, Zironi S, Del GC, Luppi G, Conte PF: Prognostic role of EGFR gene copy number and KRAS mutation in patients with locally advanced rectal cancer treated with preoperative chemoradiotherapy. Br J Cancer 2010, 103(7):1019-1024.

28. Fransen $K$, Klintenas M, Osterstrom A, Dimberg J, Monstein HJ, Soderkvist P: Mutation analysis of the BRAF, ARAF and RAF-1 genes in human colorectal adenocarcinomas. Carcinogenesis 2004, 25(4):527-533. doi:10.1093/carcin/bgh049.

29. Gaedcke J, Grade M, Jung K, Schirmer M, Jo P, Obermeyer C, Wolff HA, Herrmann MK, Beissbarth T, Becker H, Ried T, Ghadimi M: KRAS and BRAF mutations in patients with rectal cancer treated with preoperative chemoradiotherapy. Radiother Oncol 2010, 94(1):76-81.

30. Di NF, Martini M, Molinari F, Sartore-Bianchi A, Arena S, Saletti P, De DS, Mazzucchelli L, Frattini M, Siena S, Bardelli A: Wild-type BRAF is required for response to panitumumab or cetuximab in metastatic colorectal cancer. J Clin Oncol 2008, 26(35):5705-5712.

31. Barault L, Veyrie N, Jooste V, Lecorre D, Chapusot C, Ferraz JM, Lievre A, Cortet M, Bouvier AM, Rat P, Roignot P, Faivre J, Laurent-Puig P, Piard F: Mutations in the RAS-MAPK, PI(3)K (phosphatidylinositol-3-OH kinase) signaling network correlate with poor survival in a population-based series of colon cancers. Int J Cancer 2008, 122(10):2255-2259. doi:10.1002/ijc.23388.

32. He Y, Van't Veer L, Lopez-Yurda M, van de Velde CJ, Marijnen CA: Do rectal cancer patients with PIK3CA mutations benefit from preoperative radiotherapy with regard to local recurrences? Clin Cancer Res 2010, 16(24):6179.

33. Michelassi F, Vannucci LE, Montag A, Chappell R, Rodgers J, Block GE: Ras oncogene expression as a prognostic indicator in rectal adenocarcinoma. J Surg Res 1988, 45(1):15-20.

34. Grana TM, Rusyn EV, Zhou H, Sartor Cl, Cox AD: Ras mediates radioresistance through both phosphatidylinositol 3-kinase-dependent and Raf-dependent but mitogen-activated protein kinase/extracellular signal-regulated kinase kinase-independent signaling pathways. Cancer Res 2002, 62(14):4142-4150

35. Bengala C, Bettelli S, Bertolini F, Salvi S, Chiara S, Sonaglio C, Losi L, Bigiani N, Sartori G, Dealis C, Malavasi N, D'Amico R, Luppi G, Gatteschi B, Maiorana A, Conte PF: Epidermal growth factor receptor gene copy number, K-ras mutation and pathological response to preoperative cetuximab, 5-FU and radiation therapy in locally advanced rectal cancer. Ann Oncol 2009, 20(3):469-474

36. Zauber NP, Marotta SP, Berman E, Grann A, Rao M, Komati N, Ribiero K, Bishop DT: Molecular genetic changes associated with colorectal carcinogenesis are not prognostic for tumor regression following preoperative chemoradiation of rectal carcinoma. Int I Radiat Oncol Biol Phys 2009, 74(2):472-476.

37. Davies JM, Trembath D, Deal AM, Funkhouser WK, Calvo BF, Finnegan T, Weck KE, Tepper JE, O'Neil BH: Phospho-ERK and AKT status, but not KRAS mutation status, are associated with outcomes in rectal cancer treated with chemoradiotherapy. Radiat Oncol 2011, 6:114.

doi:10.1186/1471-2407-13-200

Cite this article as: Derbel et al: Impact of KRAS, BRAF and PI3KCA mutations in rectal carcinomas treated with neoadjuvant radiochemotherapy and surgery. BMC Cancer 2013 13:200. 